\title{
Extractivismo forestal, centralismo neoliberal y Pobreza Estructural del Itata (Chile)
}

\author{
Forest extractivism, neoliberal centralism and Structural Poverty of Itata (Chile)
}

\author{
Germán Catalán Ovalle* \\ Esteban Valenzuela Van Treek ${ }^{* *}$
}

\begin{abstract}
Resumen: La provincia más pobre de Chile coincide con el monocultivo forestal, domina dos tercios del territorio, predominando el extractivismo en el centro sur de Chile que, empobrecido por combinación de monocultivo, neoliberalismo con baja tributación, centralismo sin poder ni planificación territorial, baja industrialización y ausencia de fondos de convergencia, lo que impide el desarrollo endógeno. Grupo Angelini se quedó con la celulosa privatizada por Pinochet, la cual se expande por el mundo en un caso de transnacionalización por desposesión. Salir de la pobreza se vincula a limitar el extractivismo, alta tributación local para diversificar economía, descentralización sustantiva y enfoque sustentable.
\end{abstract}

Palabras Clave: extractivismo, forestales, Chile, Itata, desarrollo territorial.

Abstract: The poorest province of Chile coincides with the forest monoculture which dominates two thirds of the territory, predominant in the extractivism of the south-central zone of Chile, impoverished by the combination of monocultuve, neoliberalism with low taxation, centralism without power or territorial planning, low industrialization and the absence of structural convergence funds, which prevents endogenous development. The Angelini Group was left with the cellulose privatized by Pinochet, which expands around the world in a case of transnationalization by dispossession. The solution to this structural poverty is a mix of limiting extractivism, high local taxation to diversify the economy, substantive decentralization and a sustainable approach.

Key Words: extractivism, forestry, Chile, Itata, territorial development.

Recibido: 3 marzo 2021 Aceptado: 15 mayo 2021

\section{Introducción: cooptación y rezago estructural de regiones forestal.}

\footnotetext{
* Germán Catalán Ovalle: Periodista, Universidad del Desarrollo, Magíster en política y gobierno, Universidad de Concepción. Coordinador Ejecutivo de CREASUR Universidad de Concepción. Investigador de equidad territorial, gobernanza local y desarrollo sostenible.germancatalanovalle@gmail.com

** Esteban Valenzuela Van Treek: Periodista y Magíster en ciencia política Pontifica Universidad Católica de Chile, Magíster en Desarrollo y Gestión Pública en la Universidad de Wisconsin, Doctor en Historia Contemporánea Universidad de Valencia. Director Convergencias Regionalistas de Estudios Aplicados del Sur, CREASUR, Universidad de Concepción. Experto en gobernanza, desarrollo y descentralización, evalenzuelavt@gmail.com
} 


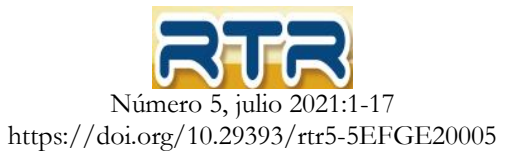

La industria forestal en Chile fue propiciada por el Estado en el período desarrollista de las revoluciones en libertad de Frei y Vía Chilena al Socialismo de Allende (1964-73) que incluyó el apoyo a la plantación de pino radiata y eucaliptus en el centro sur costero y la construcción de plantas de celulosa en Constitución y Arauco, las que luego son privatizadas en la dictadura de Pinochet en 1979 creándose la empresa CELCO del Grupo Angelini, principal actor de modelo forestal concentrador y depreciador del territorio por la agudización del despoblamiento, fin de otras actividades agrícolas (granos, ganadería), malos salarios, aniquilación del bosque nativo, pérdida atractivos turísticos y vulnerabilidad a mega incendios (Astorga y Burschel (2019). El neoliberalismo acrecentó el subsidio a la plantación de monocultivos que dominan el sur con la mayor pobreza del país (IDERE 2019), lo que configura un caso paradigmático de crecimiento por desposesión (Harley 2007) ya que el Grupo Angelini logró a bajo precio CELCO en las cuestionadas privatizaciones de Pinochet llamadas saqueo al Estado (Mönckeberg 2001) y en un esquema neoliberal centralista -baja tributación, nula regulación a las plantaciones y centralización impositiva y empresarial- a tres continentes desde su base en territorios empobrecidos de la costa centro sur de Chile. El diario empresarial El Mercurio (2017) calculó en siete billones de dólares los activos en plantas de celulosa y aglomerados de CELCO, ubicados el 40\% en Argentina, Brasil, México, USA y Europa.

Las antiguas provincias celebraban los polos industriales en su período desarrollista desde 1938 a 1973 como parte de la desconcentración, sin observar el daño ambiental estratégico que se aceleró en el período de la dictadura neoliberal con la apuesta a liberalización de la economía (Asenjo, 1992) donde se abrió paso a la inversión extranjera y la instalación de transnacionales en post de la extracción y exportación de materias primas generando un aumento en la producción minera, forestal y pesquera (Geisse, 1990). De esta manera, se abrió paso a casos como de Tiltil como zona de vertederos en la región Metropolitana, se agudizan las zonas de industrias contaminantes en Tocopilla, Calama, Mejillones, Puchuncaví-Quintero en la zona centro-norte y el eje Talcahuano-Penco y Coronel, donde se combinan pesqueras, termoeléctricas y fundiciones con puertos que manejan carbón y petróleo (Terram, 2014; OCDE, 2015).

El boom de los commodities ha legitimado el llamado neo extractivismo que busca capturar más renta, hacer política social y encubrir el daño ambiental, incluyendo países liberales. No obstante, el aumento de los ingresos fiscales y las políticas asistencialistas en América Latina producto del boom minero, petrolero y de la soya (CEPAL-GIZ ,2012), extienden la crítica al modelo. Daher (2003) llama región commodities a aquella que depende de uno o dos productos sin diversificar su economía. Esta industria ha liderado a nivel global lo que Harvey (2007) llamó el crecimiento por desposesión de amplios territorios y países enteros que son controlados por multinacionales o empresas estatales corruptas que extraen con baja tributación, explotación salarial y altos pasivos ambientales.

El propio Michael Porter (1997) que apoyó entusiasta el auge económico del sur por la vía de usar las ventajas competitivas de sus recursos naturales para el mercado mundial ( el boom de los hidrocarburos; bananos y camarones ecuatorianos; soja y cereales de Argentina y Brasil; cobre, pesca y celulosa de Chile), reguló para insistir que dicho modelo caminaba al fracaso si no sembraba en una competitividad sistémica que movilizara y enriqueciera el capital social territorial para aliarse en cluster productivos, desarrollo de proveedores locales, cooperación universidades-regiones en base a significativa tributación empresarial para el desarrollo de los territorios (Porter y Kramer 2006).

En el caso de Chile se observa la alta conflictividad territorial a partir de la falta de credibilidad de la propias industrias extractivas como las sucesivas crisis en la industria del salmón por sobre explotación 


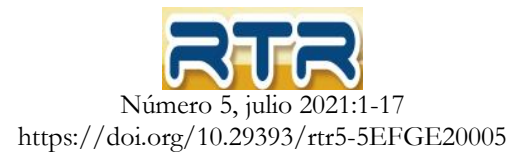

(Ramos 2014), mineras por la alta contaminación de sus ciudades como contraste en el ciclo de súper precios del cobre (OCDE 2015) y el mal uso de la llamada responsabilidad social empresarial (RSE) envilecida en cooptación usada en zonas de sacrificio como el caso de la grave contaminación de la zona industrial de Quintero-Puchuncaví en Chile- crisis de aguda contaminación del aire que implicó desde el 2018 cierre de colegios- la que había sido anunciada por investigadores que denunciaron los sistema de compra de dirigentes, políticos y sectores vecinales por parte de las empresas privadas y públicas en formas de extorsión subordinada (Sabatini, Mena y Vergara, 1997). La banalización de la RSE implica un giro hacia otras formas de ser de las empresas en los territorios que se propone como giro hacia empresas tres V: veraces en el pago de sus tributos, verdes en su compromiso con la sustentabilidad y vinculadas en su capacidad de aliarse para el desarrollo de los territorios donde extraen su riqueza (Valenzuela y Kowszyk 2017).

Gudynas (2009) usa el concepto neoextractivismo para diferenciarlo del extractivismo convencional, en el cual el Estado no juega un rol regulador del buen uso del recurso natural ni recolecta renta que permita una trasformación social. Se establecen mecanismos para resarcir a quienes no se benefician, cosa que el mercado, por sí solo, no haría (Portillo, 2014). Sin embargo, la crisis de los commodities desde el 2013 y los problemas económicos y de corrupción en el continente, reabren el debate respecto a la fragilidad de modelos extractivistas, aunque se les catalogue de neo, como lo expresa la opinión de los verdes alemanes (Lander, 2014).

Salinas y Garrido (2003) reconocen que en Chile destaca ante los conflictos medio ambientales la cooptación, esta es una alternativa no democrática para la resolución de conflictos medio ambientales La cooptación busca mantener el poder y la estabilidad del grupo dominante, requiere del manejo y distribución de recursos hacia las comunidades, en tanto, promueven el mantenimiento del poder del régimen de turno (Autor y Yévenes, 2015).

El medio empresarial chileno ha vivido casos graves de corrupción, colusión empresarial y compra de parte relevante la clase política chilena (Mayol, 2013 y 2016), que en la industria extractivista aliada con segmentos públicos se ha traducido en innumerables casos de prebendas y negligencia por falta de autonomía supervisora- desde vertidos ocultos de empresas celulosas en ríos, sobreexplotación de recursos pesqueros, integración de directivos políticos a los gremios empresariales. La industria forestal en sus dos principales matrices, CELCO de los Angelini con su origen en la industria pesquera, y el Grupo Matte dueña de la Compañía Manufacturera de Papeles y Cartones (CMPC), han sido parte de serios escándalos de vertidos de riles contaminantes de manera fraudulenta a diferentes cuencas Mataquito, Itata, Calle-Calle en Valdivia- por lo cual fueron juzgados por tribunales (Terram 2014), así como colusión en el precio del papel y sistemas de pagos ilícitos de financiamiento de la política (Castañeda 2020).

Lo anterior en Chile se evalúa como consolidación de relaciones pre modernas (Salazar 2003) y masivos sistemas de cooptación de actores políticos, funcionarios públicos y sociales (Alonso, 2007; Durston, 2012), en una relación asimétrica entre un "patrón" que controla recursos y un cliente que los acoge a cambio de lealtad política (Arriagada, 2013). Cuando hay daño se busca compensar de manera monetaria con bonos a actores conflictivos por parte de agencias estatales e industrias contaminantes (Vidal 2007; Figueroa, Asenjo, Valdés y Praus, 2005).

En Chile no hay ley de rentas regionales que permita a las regiones disponer de recursos para esta diversificación desde impuestos al uso de sus recursos naturales (aire, puerto, borde costero, en estos casos de estudio), por la vía de que se creen nuevos emprendimientos y mejora de su capital social 
integral como se propone en la teoría de clúster (Porter y Kramer 2006; Comisión para la descentralización 2014).

\section{Metodología: Contrastar indicadores socioeconómicos y acciones de la industria}

El estudio bibliográfico, documental y de entrevistas cualitativas se focaliza en las provincias del Itata (actual Región de Nuble) donde se ubica la mega planta de CELCO Nueva Aldea, la más pobres del país (PNUD 2018), Se indaga los niveles de desarrollo humano en comunas seleccionadas corroborando que sigan la mista contradicción que un equipo de investigadores del Centro Latinoamericano de Demografía, descubrió al analizar en detalle las condiciones sociales de las comunas de Trehuaco, Portezuelo y Coelemu del Itata, además de San Rosendo (Biobío) y Curacautin (Araucanía): donde están las forestales hay pobreza extrema, falta de valor, malos salarios y externalidades negativas con un casi inexistente vínculo con el territorio y su comunidades (Martínez 1997).

En ambos casos se compararán sus indicadores de pobreza multifactorial con los promedios nacionales, se indagará en el nivel de encadenamiento industrial con las bases de datos disponibles y los informes de responsabilidad social empresarial de la propia industria. También se usarán entrevistas cualitativas a un ex directivo de CELCO, un alcalde mapuche y dos directivos universitarios que trabajan en la industria y dos profesionales del sector público que inter locutaron con la industria en promoción agrícola, realizadas durante mayo del año 2020. Las entrevistas son anónimas y hacen referencia al rol de los mismos).

\section{Pobreza estructural con ausencia de contribución y regulación forestal.}

Durante los treinta años de implementación del modelo de industrialización para substitución de importaciones (ISI), 1935-1975, la zona sur con su eje en Concepción se convirtió en el segundo polo industrial de Chile tras Santiago, con una fuerte industria del carbón y el acero, pesca, plástico, petroquímica, refinerías de petróleo, textiles (Ovejas Tomé), porcelana (Fanaloza), y las zonas rurales fueron productoras de leche, hortalizas, granos y vides hacia el Valle del Itata. Frei y Allende introducen lo forestal como complemento para la zona costera con erosión y dunas, pero la dictadura de Pinochet abre la economía, se produce la desindustrialización, exceptuando las celulosas que se nutren desde 1974 con el decreto de Ley 701 que les financió la forestación masiva de pino radiata y luego eucaliptus.

En el caso de la región de Nuble, que comparte con la Araucanía el ser las más pobres del país, las plantaciones forestales entre el 2008 y 2015 aumentaron a un promedio del nueve por ciento anual (Flacso, 2018)). La región de Nuble posee un territorio de $13 \mathrm{mil} \mathrm{km} 2$, y las cuatro comunas que se estudiadas, Coelemu, Cobquecura, Ninhue y Quirihue que suman dos mil $\mathrm{km} 2$ y es donde se concentran en el $14 \%$ de la región el $40 \%$ de sus plantaciones forestales.

A juicio de Fawaz (2000) la expansión forestal no ha contribuido a aminorar las brechas sociales y aislamientos territoriales como tampoco ha aportado a mejorar los niveles de pobreza local. Sin clúster industrial nada de industria del mueble ni de viviendas a gran escala salvo la celulosa y en un porcentaje menor aglomerados y aserraderos, convirtió al sur en una mancha de monocultivo con alto conflicto con los mapuches, los sistemas de agua comunitarios, los viñateros artesanales, el turismo y los grupos ambientalistas. 
La mitad de las tierras útiles de la región de Nuble se destinan a los forestal, un $12 \%$ a praderas y un 30\% a agricultura (Flacso, 2018). De este modo, Nuble se convirtió en el clásico territorio de extracción de recursos naturales, en gran volumen o alta intensidad, y que están orientados esencialmente a ser exportados como materias primas sin procesar, o con un procesamiento mínimo (Gudynas, 2014). La tabla uno muestra la supremacía absoluta de los monocultivos forestales en la zona:

Tabla1: Superficie en hectáreas Plantaciones forestales Región de Ñuble Provincias al 2017 en pino radiatas y eucaliptus (E).

\begin{tabular}{|l|l|l|l|l|l|}
\hline Provincia & Pino radiata & E. globulus & E. nitens & Otras & Total \\
\hline Diguillín & 65.392 & 17.818 & 6.919 & 1.740 & 91.869 \\
\hline Itata & 70.144 & 35.578 & 862 & 2.058 & 108.642 \\
\hline Punilla & 45.826 & 15.776 & 7.628 & 1.949 & 71.179 \\
\hline Total ha & 181.326 & 69.172 & 15.409 & 5.747 & 271.690 \\
\hline
\end{tabular}

Fuente: Instituto Forestal, Anuario 2019

La industria forestal es alrededor del 2.3 del PIB, exporta en torno a 5,3 billones de dólares (INFOR, 2018), ubicándose con la pesca/acuicultura (6 billones), la agricultura/vinos (10 billones) y la manufactura (ocho billones) entre los pilares de la economía exportadora chilena. El caso de Nuble cobra ribetes extremos la falta de clúster territorial, ya que las cuatro comunas de mayor presencia forestal en la costa de dicha región, muestra a dos comunas sin ni siquiera un aserradero, y las dos más populosas de la provincia del Itata, Coelemu y Quirihue, con una participación menor. La tabla dos muestras en el Itata la existencia de sólo algunos aserraderos en las comunas estudiadas:

Tabla 2: Unidades productivas de la industria forestal en Chile y en cuatro comunas de la Provincia del Itata, Región de Ñuble.

\begin{tabular}{|l|l|l|l|l|l|}
\hline Industria forestal & Chile & Cobquecura & Coelemu & Ninhue & Quirihue \\
\hline Aserrío Desocupad & 984 & 0 & 5 & 0 & 5 \\
\hline Astillas & 193 & 0 & 4 & 0 & 4 \\
\hline Polines y postes & 92 & 0 & 2 & 0 & 3 \\
\hline Tabletas y chapas & 28 & 0 & 2 & 0 & 0 \\
\hline Pulpa y papel & 11 & 0 & 0 & 0 & 0 \\
\hline Total & 1.308 & 0 & 13 & 0 & 12 \\
\hline
\end{tabular}

Fuente: Elaboración propia a partir de los datos del Instituto Forestal 2019.

\section{Precariedad en comunas forestales}

Los sueldos promedios de las comunas estudiadas de la provincia del Itata en Ñuble son un 43,3\% más bajos que el promedio nacional, al igual que las provincias forestales de la Araucanía y Maule, concentran los mayores niveles de pobreza junto a la Región de Los Lagos. El sueldo promedio bruto es en Nuble es 611 mil pesos mientras que a nivel país se eleva a $\$ 826$ mil. La provincia del Itata en la 
costa de Ñuble es la peor del país con un promedio de sólo 531 mil pesos (600 dólares al 2019), siendo paupérrimo en Cobquecura donde reciben un poco más que la mitad del promedio nacional.

Tabla 3: Sueldo bruto por comunas seleccionadas del Itata comparado con el sueldo promedio bruto del país

\begin{tabular}{|l|l|c|}
\hline Comunas & $\begin{array}{l}\text { Sueldo promedio } \\
\text { por persona }\end{array}$ & $\begin{array}{l}\text { Sueldo promedio país } \\
\text { por persona } \$ 825.986 .-\end{array}$ \\
\hline Coelemu & $\$ 607.387 .-$ & $73,53 \%$ \\
\hline Cobquecura & $\$ 459.015 .-$ & $55,57 \%$ \\
\hline Ninhue & $\$ 497.627 .-$ & $60,24 \%$ \\
\hline Quirihue & $\$ 520.021 .-$ & $62,95 \%$ \\
\hline País & $\$ 825.986 .-$ & $100 \%$ \\
\hline
\end{tabular}

Fuente: Ministerio del Trabajo, Sistema de Información Laboral (SIL), 2019.

Según los datos del Censo 2017 realizado en Chile, las comunas del Itata muestran también precariedad en el empleo con sólo en promedio en estas comunas de un $44 \%$ que declara estar trabajando versus un $58 \%$ a nivel nacional. Es decir, la plantación forestal que estructuralmente genera poco empleo por el trabajo estacional de raleo y corte de árboles de manera esporádica tiene que efecto de lucro cesante para los territorios el minimizar la agricultura tradicional que es intensiva en mano de obra. Entre las mujeres llega a niveles mínimos en el país con sólo un 35\% que declara trabajar fuera del hogar en los territorios forestales. Dichas comunas forestales son las más pobres del país y de la región con un promedio de $35 \%$ de población en pobreza multidimensional versus el $20 \%$ en el país (CASEN, 2017).

El despoblamiento es otra dimensión que agudiza el monocultivo forestal que se refleja en la gran cantidad de viviendas desocupadas, envejecimiento de la población y mala calidad de la vivienda que es una dimensión esencial (Alkire \& Foster, 2011) (MDS, 2016).La Tabla 4 muestra que el acceso de agua en las viviendas en las comunas forestales es dramáticamente deficitario llegando a niveles de sólo un tercio en Ninhue versus el $93 \%$ de promedio nacional.

Tabla 4: Porcentaje uso y calidad de la vivienda con acceso a agua comunas Itata versus promedios nacionales

\begin{tabular}{|l|l|l|l|l|l|}
\hline Vivienda & Chile & Cobquecura & Coelemu & Ninhue & Quirihue \\
\hline Vivienda desocupada & 11 & 38 & 11 & 14 & 11 \\
\hline Hacinamiento & 7 & 4 & 6 & 4 & 5 \\
\hline Red pública de agua & 93 & 47 & 69 & 31 & 79 \\
\hline$*$ IM aceptable & 83 & 61 & 78 & 66 & 72 \\
\hline *IM recuperable & 15 & 35 & 21 & 32 & 25 \\
\hline$*$ IM irrecuperable & 2 & 4 & 1 & 2 & 3 \\
\hline
\end{tabular}

Fuente: Censo 2017, Instituto Nacional de Estadística (INE).

Todos los indicadores de educación son deficitarios en las comunas forestales, con niveles de sólo 14\% de jóvenes que acceden a la educación superior versus el 31\% a nivel nacional debido tanto a los malos resultados en las pruebas de acceso a la universidad como en la nula oferta de educación técnico superior en la provincia del Itata, con absoluta ausencia de labor en esta dimensión de las forestales. 
Salvo Ninhue, es la comuna que destaca en matemáticas (SIMCE, 2018). Como contraste de esta cruda realidad, los colegios guetos elitistas de los profesionales de celulosa Arauco (Grupo Angelini) en Constitución, Yumbel y Arauco se ubican entre los mejores del país sin colaboración relevante con la educación pública de sus territorios plantaciones. Como el Colegio Los Cipreses creado por Agrosuper, él que se ubicó como el mejor subvencionado de la región de O’Higgins (SIMCE 2018). En Salud se ratifica el rezago de las zonas forestales con los perores datos nacionales en las mediciones conocidas de mortalidad infantil (MINSAL, 2015)en que las comunas del Itata se ubican en torno al 16\% versus el $7 \%$ del promedio nacional.

\section{Los bajos ingresos municipales y la ausencia de tributación forestal}

A diferencia de la actividad minera, acuícola y de casinos de juego que tienen patentes específicas de impacto municipal y regional, la industria forestal no tributa territorialmente y está exenta del pago de impuestos prediales incluyendo sus plantas industriales. Los municipios forestales, carentes de base fiscal propia, dependen de las transferencias que le llegan del Fondo Común Municipal que se nutre de los ingresos de comunas de clase media alta (SINIM, 2018). Los ingresos propios permanentes de estos municipios forestales son sólo en torno a un tercio del promedio de los municipios del país, logrando Cobquecura alguna renta por las casas vacacionales de sus enclaves de balnearios costeros. "En la comuna de Portezuelo ni siquiera están conectados con asfalto y la zona costina tiene un pequeño enclave turístico en Buchupureo. El resto vivió un abandono completo de la Región del Biobío y de la industria forestal", opina un ex consejero regional por Chillán.

Por su parte, el principal productor de tinajas para saunas y productor de vinos Cinsault en la localidad de Guarilihue de la comuna de Coelemu es categórico contra la celulosa: "En 1995 tuvimos que agruparnos como Viñas del Itata porque la planta de CELCO en Nueva Aldea estaban en expansión y contaminó varias veces el río, movilizándonos para obligarles a mejorar sus filtros y hacer un ducto hacia el mar. Aquí en Guarilihue somos comarca verde productiva y solo un vecino vive de las forestales con su pequeño aserradero". La Tabla 5 nos muestra la precariedad presupuestaria municipal en el Itata:

Tabla 5: Promedio ingresos permanentes de las comunas y a nivel país

\begin{tabular}{|l|l|c|}
\hline Comunas & IPP & IPP $\%$ del promedio del país \\
\hline Coelemu & $\$ 24.890 .-$ & $30,14 \%$ \\
\hline Quirihue & $\$ 20.740 .-$ & $25,11 \%$ \\
\hline Cobquecura & $\$ 49.470 .-$ & $59,91 \%$ \\
\hline Ninhue & $\$ 23.840 .-$ & $28,87 \%$ \\
\hline País & $\$ 82.570 . .^{-}$ & $100 \%$ \\
\hline
\end{tabular}

Fuente: Elaboración propia en base a Senado de la República de Chile, datos de Unidad Presupuestaria del Senado.

\section{El bajo compromiso territorial relevante de la mayor celulosa de Chile.}

La Comisión para la Descentralización 2014 había propuesta un mega fondo de convergencia territorial que favorecía al centro sur pobre en base a royalties a los recursos naturales incluyendo el pago territorial de las forestales por tala de hectáreas de bosques y el fin de las exenciones tributarias del impuesto predial para la significativa correlación entre la desigualdad en el ingreso regional y los ingresos tributarios propios de los gobiernos intermedios en la economías de América Latina (Muñoz, 


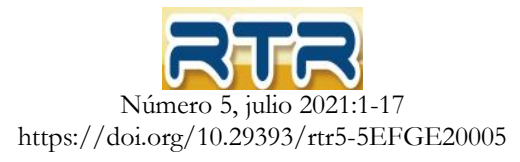

Radics y Bone 2016).

Al analizar el Informe de Sostenibilidad de CELCO (Arauco 2019) se observa su bajo aporte con proyectos territoriales con solo diez millones de dólares en todos los países en que opera, la graduación de 37 técnicos en mantención en Nueva Aldea (Itata) y un número no especificado de personas formadas en sus sistemas de educación dual en Arauco, donde la mayoría lo hace en las faenas forestales y plantes de celulosa, siendo incipiente el área maderas. El informe no especifica acciones en los hitos relevantes con empresas tecnológicas y universidades de la Región del Biobío y si menciona un convenio con el MIT de Boston en tres productos. Es claro el foco de la empresa en su expansión a los nuevos países (México, USA) y la casi total ausencia de alianzas de valor en sus territorios originales de Chile entre el Maule (Constitución) y Los Ríos (Mariquina). El mismo reporte reconoce sus ventas 2018 por casi seis mil millones de dólares, con la expresión "cerca diez millones de dólares para más de 50 programas de desarrollo" a nivel global (Arauco 2019:78). Agregan en su historial proyecto de apoyo a educación en comunidades mapuches desde el 2012.

El resultado depreciador del territorio y comunidades- verbo transitivo de perder valor- es también considerado como caso emblemático en Chile de la teoría implosión/explosión urbana Brenner (2013) aplicado en Chile a territorios mineros y forestales productivos versus el Barrio Alto de Santiago que acumula las ventas y las empresas administradoras donde cuentan con altos estándares urbanos (Vergara-Perucich 2018), lo que se traduce en este fenómeno depreciador y despreciativo de los territorios de producción (Arboleda 2015).

El estudio Extractivas en transformación por la resistencia territorial en Chile: Giro 3 V (Verdes, Veraces y Valorativas) (2014), los autores manifiestan la relevancia de contar con empresas que desarrollen este tipo de visiones de la responsabilidad social empresarial. Empresas que deben poseer un viraje a las $3 \mathrm{~V}$ orientadas a la sustentabilidad, en el ámbito veraz, cumpliendo con la ley, el pago de impuestos, trabajando de forma transparente, colaborativa y participativa con la sociedad. Verde, pensando en el Desarrollo Sostenible, en las bajas emisiones, energía asequible y no contaminante donde mejore el entorno no solo se recupere. Valoradas, que se trabaje con los territorios, regiones, localidades, donde prime una relación laboral proactiva, vinculada a una alianza público- privada entre multi actores (Valenzuela \& Kowszyk, 2017).

En virtud de esto, CELCO, la principal empresa de celulosa chilena generó daños ambientales irreversibles en 2004, en la zona sur de Chile, no siendo transparente en su actuar, vertiendo elementos nocivos a las aguas y ríos produciendo muerte en la flora y fauna, entre ellos miles de cisnes cuello largo en Valdivia (Valenzuela \& Kowszyk, 2017).

A esto se le suma la falta de RSE de la misma empresa y su larga lista de antecedentes al medio ambiente entre los que se menciona el ocurrido en 2011 con el derrame de riles en el estero Velenunque, en la localidad de Ránquil, en la actual región de Ñuble, o dos años después, derrame de residuos líquidos industriales (RIL) en Boca Itata, sector de Trehuaco, la fuente de la salida de los residuos la Planta de Nueva Aldea de CELCO y por último el hecho ocurrido en el Golfo de Arauco, en 2004, con el derrame de cinco mil litros de trementina y $15 \mathrm{mil}$ litros mezcla de agua y elementos químicos lo que provocó una mancha negra en el mar provocando intoxicación en balnearios aledaños (TheClinic, 2015)

En el sector de Nueva Aldea, Nuble, se instaló la celulosa CELCO a comienzos de siglo, lo que ha traído consecuencias para las comunidades aledañas a su planta, los vecinos manifiestan sentirse expuestos a agentes contaminantes, el desarrollo de este tipo de proyectos pone en peligro el entorno, 
no existe una relación de trabajos colaborativos o vinculados entre empresa - comunidad (Ojeda, Cancino, Carabante, Cisterna, \& Díaz, s.f.).

La dinámica de desarrollo que tiene CELCO en la región de Maule ha logrado que mejorar las condiciones salariales de sus trabajadores y mejorar la calidad del empleo, sin embargo, ha dotado de menor protagonismo a las organizaciones sociales, las ha invisibilizado e influencia como holding ha minorizado a sus grupos de interés lo que ha conllevado a que las demandas socio ambientales se vean desvalidas como el Sindicato de Pescadores de Constitución, por lo que se traduce en una empresa que no trabaja con sus stakeholders y solo da valor a los territorios que ellos estimen conveniente, no mejorando la calidad de vida de los vecinos de su mega industria, matando el turismo por problemas medio ambientales y las plantaciones agrícolas tuvieron que transformarse (Fernández, Fernández, \& Fuentealba, 2014).

CELCO ha propiciado la introducción de elementos exóticos como el pino lo que genera efectos negativos en los territorios debido a el consumo de agua de este árbol y la industrialización y mecanización de las labores lo que perjudica al mercado laboral (Fernández, Fernández, \& Fuentealba, 2014).

Lo tradicional se está perdiendo por la entrada de las forestales en los territorios, es el caso de las cepas del Valle del Itata, lugar de viñateros que se ve afectado y ha tenido que formar liderazgos colectivos para participar en el mercado y como relacionarse con la industria forestal, lo que genera una tensión permanente, perjudicando la identidad territorial, el valor de la historia y el paisaje patrimonial (Méndez, 2016).

Las problemáticas y conflictos que esta mega industria genera valida a la idea de Valenzuela y Kowszyk, que plantean que para que una empresa sea sustentable debe ser veraz, verde y valorativas lo que contradice las prácticas que emplea CELCO y que origina problemas socio ambientales en los territorios en donde operan.

Las entrevistas a actores relevantes reconocieron el vínculo parcial de la industria por proyectos medianos sin financiamiento estructural que se acercan más a formas cooptativas que transformadoras funcionales a un modelo global funcional a la estrategia de desarrollo regional que apuesta al Gran Concepción como puerto global de industria forestal y pesquera como región commodities (Daher 2003), naturalizando anomalías que además permiten a las empresas comprar con incentivos individuales (Bauman, 1999) no obstante la privación de empleo de calidad estructural que afecta a las provincias aledañas a la gran ciudad del sur de Chile. De hecho, en el Índice de Calidad de Vida Urbana, ICVU(2019), de la Universidad Católica, sorprende el avance de las comunas de la zona conurbada de Concepción, San Pedro La Paz, Talcahuano ubicadas entre las 15 comunas de mayor desarrollo de Chile, versus el rezago de Chillán (Nuble), Los Ángeles y las comunas más ligadas a lo forestal al norte y sur de la ciudad como Tomé-Penco y Lota.

El proyecto primario exportador forja la dependencia a los mercados internacionales y no contribuye a una mejora sustancial en la calidad del empleo en América Latina como fenómeno histórico (Zapata 2001). El neoextractivismo es la continuidad de la misma idea de apostar a ventajas en materias primas y una industrialización menor vinculada a fundiciones lo que no genera buen empleo y sostenibilidad en el largo plazo (Gudynas 2009), sometido además a las regiones commodities a los vaivenes de los precios mundiales (Daher 2003). La extracción exacerbada de materias primas, priorizan el desarrollo económico nacional, por sobre la conservación y/o cuidado de la naturaleza y la transformación 
productiva de los territorios sostenible.

Usamos el concepto de "mitigación cooptadora" ya que las regulaciones ambientales introdujeron mejoras menores a los proyectos existentes, junto con legitimar procesos de diálogo y aportes menores vía proyectos o coparticipación en patentes mineras o acuícolas, en el caso de las forestales planes sociales y comunales menores que no son un giro estructural hacia empresas. En ese sentido, también es clave destacar que la relación ciudadanos-Estado debe ir más allá del enfoque de ingresos por vía de la estructura impositiva, ya que, en materia de control social, la ciudadanía juega un rol esencial en ser agentes activos en la fiscalización, en el paradigma de nuevas relaciones con el Estado.

La centralización en Chile agudiza el accionar extractivista al no existir competencias que permitan actuar a los gobiernos regionales como entes autónomos que puedan planificar los territorios para contener el monocultivo, hacerlo compatible con el bosque nativo, otras actividades agropecuarios y ganaderas que eviten el peligro de mega incendios (Astorga y Burschel 2019). Las regiones sufren las tragedias y no tienen poder. Recién se avanza en la idea de Plan Regional de Ordenamiento Territorial (PROT). No tienen potestad alguna en el borde costero: "Todo está centralizado, nos tienen haciendo mapitas banales y la industria con los ministerios vetaron la tramitación del PROT que pedía condiciones a la inversión forestal con el objeto de regularla sin prohibirla (profesional Gobierno Regional del Biobío)".

El Estado sufre de cierta anomalía en su relación con los territorios, primero por no ser responsable en generar un marco jurídico que vele por la función esencial de este que es avanzar hacia el bien común. Este, fomentó la instalación de las empresas y luego facilitó la invasión de ambos lugares por capitales nacionales y transnacionales, esto al más puro manto de las coaliciones políticas gobernantes posrégimen autoritario, quienes al verse favorecidas por esta complicidad no cumplieron con dos cuestiones básicas del neo extractivismo: que los territorios sean parte en un Estado descentralizado del rol intermediario como ente regulador y fiscalizador, entre las industrias y la ciudadanía. Por otra parte, es económicamente activo, se ha reestructurado para proteger la alianza Estado y hegemonía económica en pro del nuevo extractivismo.

En investigación y desarrollo para crear valor un ex directivo de la Universidad del Biobío dice "el aporte de CELCO y CORMA (Corporación de la Madera) tiene valor al sistema de innovación de la Región porque el estándar y el aporte privado es mínimo. Sin embargo, si se ve en perspectiva, no debe alcanzar los cinco millones de dólares anuales lo que es muy bajo y muchas veces son aportes complementarios a los fondos de innovación que ganan las universidades con el Consejo Regional". Por su parte, un experto en innovación de la Universidad de Concepción reconoce que las celulosas hacen aportes "puntuales a que se materialice el sueño regional del Parque Científico y Tecnológico de Concepción, pero no se han comprometido a un financiamiento basal de mediano plazo, no crean divisiones de investigación relevantes como los escandinavos".

\section{Conclusiones: Extractivismo empobrecedor sin salto al desarrollo sostenible}

En síntesis, no se cumple en lo esencial que es cobrar impuestos y compartir la renta por dicha industria con los territorios para dar sustentabilidad a los clústeres, la asociatividad industria-universidades, el desarrollo de servicios conexos y un encadenamiento sustancial y sostenible en el tiempo (Porter 1997) para que no sean intervenciones episódicas y se articule una verdadera estrategia competitiva (Flores 2014). Las forestales funcionan como enclaves sin buscar alianza y gobernanzas multiactor con los territorios donde han nutrido su expansión en el caso de CELCO de los Angelini legando un territorio 
depreciado por el extractivismo tras medio siglo de explotación sin mayor regulación pública ni compromiso de las propias empresas. Centralismo, neoliberalismo y extractivismo han dejado sin soberanía territorial a los habitantes de la costa centro sur de Chile.

La idea neo extractivista sugiere una nueva forma de operar los recursos naturales, que va enfocado en la mayor distribución de las rentas, por una parte, los programas sociales y por el otro fortalecer el modelo productivo, cosa con actualmente no se produce. Estos cambios son proceso de largo plazo y profundizar en otro modelo productivo, dejar la dependencia del extractivismo. Se debe contar con un sistema regulado y que el Estado participe de forma directa por medio de empresas públicas (Portillo, 2014).

Los resultados obtenidos presentan las magras condiciones socioeconómicas presentes en las Cobquecura, Coelemu, Ninhue y Quirihue, comunas pertenecientes a la provincia del Itata, región de Nuble. El extractivismo y neo extractivismo se intensificó en el territorio desde principio de 1980 lo que ha determinado que las plantaciones forestales adquieran mayor terreno en desmedro de los cultivos tradicionales que van perdiendo terreno y con ello los propietarios de estos predios tengan que vender o arrendar a empresas forestales para subsistir en zonas de pobreza rural que se ha mantenido pese a la llegada industrialización a la zona, la que estuvo detenida por mucho tiempo privilegiando otras zonas del centro sur del país.

En el Itata fracasó la idea de progreso y la investigación deja en manifiesto que persisten las más altas tasas de pobreza multidimensional y de ingresos del país solo comparables a las otras zonas forestales ubicadas en la Región del Biobío (sobre todo provincia de Arauco) y en La Araucanía (zona norte costera) donde no hay fondos de convergencia para el desarrollo, diversificación económica ni clúster relevante industrial. En lo ambiental se estable que el monocultivo daña las cuencas y la diversidad de uso del suelo, disminuyendo las actividades ganaderas y agrícolas. Además, son las zonas de mayor déficit de acceso al agua potable en los hogares tanto por la pérdida de napas superficiales como por la ausencia de fondos relevantes de desarrollo desde la propia industria de la celulosa como del Estado.

Se señala que las instalaciones de la industria forestal en Ñuble fue una política pública que, a mediados del siglo pasado, una zona que contaba con las condiciones propicias para la producción de pino y eucaliptus, además, con la perspectiva de proyectarse como una zona industrializada (Reyes,2003). Tampoco se cumplió la promesa neo extractivista de que empresas extractivistas tienen como objetivo impulsar el crecimiento económico, mayor empleabilidad, mejorar el flujo económico para otras áreas del comercio local y combatir la pobreza (Gudynas, 2011). En el Itata, la pobreza rural se mantuvo pese a la presencia extractivista debido a la no tributación y el rol subsidiario del Estado ausente que no ha generado clúster relevante ni recursos para otras áreas del desarrollo en beneficio social de las comunidades que conviven con las forestales.

Tabla 6: Comparativa promesa neo extractivista y la realidad del Itata

\begin{tabular}{|l|l|l|}
\hline Promesa & Hitos & Realidad Itata \\
\hline Mejoría Social & Disminución Pobreza & $\begin{array}{l}\text { Provincias más pobres de } \\
\text { Chile }\end{array}$ \\
\hline Clúster e Industrialización & $\begin{array}{l}\text { Proveedores locales e } \\
\text { industria en territorios }\end{array}$ & $\begin{array}{l}\text { Mega planta de celulosa en } \\
\text { Nueva Aldea con bajo } \\
\text { vínculo local }\end{array}$ \\
\hline $\begin{array}{l}\text { Coexistencia propiedad } \\
\text { pública, mixta y cooperativa }\end{array}$ & $\begin{array}{l}\text { Impulso cooperativas y apoyo } \\
\text { con empresas públicas a otros }\end{array}$ & $\begin{array}{l}\text { Dominio plantaciones privadas } \\
\text { planto }\end{array}$ \\
\hline
\end{tabular}




\begin{tabular}{|c|c|c|}
\hline En diversificación económica & desarrollos & $\begin{array}{l}\text { Sólo pequeños y pocos } \\
\text { aserraderos }\end{array}$ \\
\hline Mejora calidad del empleo & $\begin{array}{l}\text { Más empleo y mejor que el } \\
\text { rural tradicional }\end{array}$ & $\begin{array}{l}\text { Promedio salarial de sólo } \\
60 \% \text { del promedio nacional }\end{array}$ \\
\hline $\begin{array}{l}\text { Relevante tributación para el } \\
\text { desarrollo de los territorios } \\
\text { que aportan el recurso natural }\end{array}$ & $\begin{array}{l}\text { Tributos locales y programas } \\
\text { relevantes desde el Estado } \\
\text { central }\end{array}$ & $\begin{array}{l}\text { Casi nula tributación } \\
\text { territorial } \\
\text { Ausencia de ley de rentas } \\
\text { territoriales sin fondo de } \\
\text { convergencia estructural } \\
\text { Puntuales proyectos de } \\
\text { zonas de rezago }\end{array}$ \\
\hline Cuidado ambiental & $\begin{array}{l}\text { Desarrollo sostenible con } \\
\text { biodiversidad, planificación y } \\
\text { control daños. }\end{array}$ & $\begin{array}{l}\text { Monocultivo invasivo de casi } \\
78 \% \text { del territorio } \\
\text { Crisis hídrica, } \\
\text { biodiversidad } \\
\begin{array}{l}\text { Mejora parcial de } \\
\text { externalidades celulosa }\end{array}\end{array}$ \\
\hline
\end{tabular}

Fuente: Esteban Valenzuela y Germán Catalán.

El encadenamiento productivo que se manifiesta en la provincia del Valle del Itata es limitado, más aun si consideramos que en el secano costero e interior representan el $72 \%$ de del terreno arboleado y comunas como Cobquecura y Ninhue no presentan industria forestal, no hay aserradores, astilleros, ni lugares de fabricación de polines, posteros, tabletas o chapas, solo de plantaciones, recordando que Ñuble representa el 12,5\% del PIB forestal y Biobío el 27,5\%, por lo existe escaso clúster forestal en la zona considerando que Cobquecura y Ninhue son netamente de extracción de pino y eucaliptus y que perciben la menor recaudación porcentual sobre los Ingresos Propios Permanentes en sus respectivos municipios, por lo que son más dependientes del Fondo Común Municipal, por lo que es necesario una ley de rentas regionales que permita que las empresas, en este caso forestal, tributen en los territorios (Comisión Asesora Presidencial en Descentralización y Desarrollo Regional, 2014).

No hubo salto al neo extractivismo en cual es por sí un concepto rebatible como señala Acosta citando a Gudynas y que en el sur forestal no se cumplió: "Para lograrlo, el Estado capta (o intenta captar) una mayor proporción del excedente generado por los sectores extractivos. Además, parte de esos recursos financian importantes y masivos programas sociales, con lo que se aseguran nuevas fuentes de legitimación social". Y de esta manera el extractivismo asoma como indispensable para combatir la pobreza y promover el desarrollo. No hay duda, neo extractivismo es parte de una versión contemporánea del desarrollismo propia de América del Sur, donde se mantiene el mito del progreso y del desarrollo bajo una nueva hibridación cultural y política. (Acosta, 2012)

Basándonos en dilucidar si la industria forestal ha generado un clúster que permita mejorar la calidad de vida de los habitantes de estos territorios, podemos concluir que el escaso clúster forestal, un Plan Valle del Itata 2017-2019 que no incluye al sector forestal en su gestión, la no asociatividad pública - privada en esta área, tampoco el encadenamiento productivo, ni un desarrollo sustentable entre lugareños y lo forestal. Que si esto se logrará implicaría una relación exitosa, ya que se necesitan para lograr un éxito competitivo y bienestar para los habitantes como lo introduce Michael Porter. Es preciso mencionar que en el sector hotelero y de restaurantes existe un leve porcentaje más alto que en promedio del país y este podría ser mayor, recordando que hay un alto número de trabajadores que se emplea de manera informal y que estos son del aspecto comercio y trabajos en el hogar. 
Sin embargo, en las actividades inmobiliarias, empresariales, de alquiler y de construcción, las comunas se encuentran rezagas y con cifras muy por debajo del promedio nacional, evidenciando una falta de desarrollo y una falencia en la industria lo que no genera innovación, oportunidades, estimulación de nuevas empresas, alianzas estratégicas y que es producto de que el mercado busca satisfacer las necesidades centralistas donde predomine una ciudad o región, una concentración de servicios y tanto el mercado como el sector público focalizan esas demandas pero no busca la desconcentración, la descentralización para producir un crecimiento equilibrado. (Armstrong \& Taylor, 2000)

Las comunas estudiadas presentan un alto índice de actividad silvoagropecuaria, tres veces más que en el promedio del país. Se recalca que el promedio por ingresos en estas comunas es menor que el promedio del país y que el área agrícola es el que menos dinero percibe en la zona donde a su vez es el rubro donde se concentran más trabajadores, lo que describe la pobreza por ingresos que persiste. La pobreza multidimensional se posiciona como un agravante para que la gente no pueda tener una movilidad social ascendente; nula educación superior fuera de Chillán, bajo nivel escolar de los jefes o jefas de hogar, escaso acceso a servicio público como el agua o una conectividad digital y vial deficiente, una tasa de mortalidad infantil más alta que en el promedio del país, son las condiciones presentes en estos territorios con la mitad de su uso de suelo destinado a las plantaciones forestales. Esto viene a validar que el sector primario, la agricultura, pesca, silvicultura es predominante y la gente que declara trabajar en la zona es 14\% menos que en promedio del país, además, con menor escolaridad. Este tipo de economía, de exportación no contribuye a mejor la economía, ni el empleo en América latina. (Zapata, 2001)

Hace 40 años la expansión forestal se comenzó a evidenciar, rezagando las otras áreas industriales como la agricultura y sus cultivos tradicionales lo que se tradujo en la migración de las zonas rurales a la urbano, una inequidad, falta de acceso a oportunidades y la concentración espacial juegan un rol crucial al momento de acceder a una buena calidad de vida (Aroca, 2011). El rezago espacial, la centralización de los bienes y servicios modifican la articulación de las áreas lo que ha intensificado la concentración de población en zonas urbanas (Méndez, 1997). Entendiendo que existen territorios que el suelo está erosionado y dañado que no permite el cultivo tradicional como papas y legumbres y donde se mantiene el trabajo de los viñateros pese al aumento de los monocultivos pino y eucaliptus. La desertificación, la erosión y la degradación que provoca este tipo de elementos exóticos en el suelo produce una perdida substancial, los incendios forestales en lugares donde se introducen estas especies y las 6 mil hectáreas de bosque nativo que son deforestados al año, contribuye al daño de los caudales y producción hídrica (Altamirano \& Lara, 2010). Es trascendente velar por el desarrollo sostenible y que converjan las dimensiones ambiental, social y económica de una forma viable, soportable y equitativa (ONU, 1992) "El desarrollo sostenible satisface las necesidades del presente sin comprometer la capacidad de las futuras generaciones para satisfacer sus propias necesidades" (Brundtland, 1987).

El extractivismo de ser utilizado de manera integral, armónica con los territorios, con un encadenamiento productivo local, realizar producciones manufactureras, sostenible, en el interior del país genera casos exitosos. Incrementar el valor agregado a la exportación y el aprovechamiento de las tecnologías. Países desarrollados crearon políticas públicas para incentivar los procesos, la comercialización, la logística que difiere de la realidad de los países de América Latina (Machinea \& Vera, 2006). Exportar materias primas en alto volumen no transforma a un país en exportador exitoso y que los gobiernos alaban este tipo de negocio, pero que las forestales son economías de enclave con poco encadenamiento local y dependiente de la inversión extranjera. (Gudynas, 2012) 
Lo planteado por Valenzuela y Kowszyk resalta que la empresa CELCO no realiza un viraje 3V, veraz, valorativa y verde, por lo que en los lugares en donde opera no realiza trabajos colaborativos con las organizaciones sociales lugareñas provocando a su vez daños medio ambientales irreversibles como la muerte de la flora y fauna de ríos y como ya se ha mencionado, la entrada y profundización de los pinos y eucaliptus en territorios produce retroceso en otras áreas productivas como la agricultura.

A su vez, en el Valle del Itata, esta industria ha dañado el paisaje patrimonial y las cepas tradicionales donde los viñateros buscan revalorar sus cultivos, rescatar el legado de siglos, sin embargo, existe tensión entre lo forestal con la introducción de pino y eucaliptus y el enfoque de lo tradicional. Existe conflicto entre lo tradicional y el ingreso de las forestales a la zona y su protagonismo territorial que afecta a las comunidades, emprendedores donde este lugar quiere rescatar su participación como actor en lo enoturismo (Méndez, 2016).

Empresa como CELCO, ubicada en Ránquil, ha aportado a que este sistema extractivista se profundice, que no exista un clúster relevante o encadenamiento productivo. El transporte de la tala, las maquinarias, la tecnología empleada y el sistema capitalista junto con los cambios de uso de suelo de agrícola a forestal, un calentamiento global que amenaza la producción con los incendios, a esto, sumando la subcontratación de empleados con bajos salarios y con la sustitución de mano de obra de baja calificación por innovación, mantiene la pobreza y desigualdad, considerando que, el modelo chileno sigue las líneas de los países desarrollados lo que se presume que en el futuro tendrá un límite la generación de empleo (Alarcón, 2018).

\section{Bibliografía}

Acosta, Alberto (2012). Extractivismo y neoextractivismo: dos caras de la misma maldición [en linea].

Disponible en

<https://www.ecoportal.net/temasespeciales/mineria/extractivismo_y_neoextractivismo_dos_caras_de_la _misma_maldicion> (consulta: 16 de octubre de 2020).

Alarcón, Cristián (2018). "Conflictividad social-ecológica, ecología política del capitalismo neoliberal e ideología de los recursos naturales en Chile". En Chile del Siglo XXI: Propuestas desde la Economía, coordinado por Diego Calderón y Felipe Gajardo, 133-154 O. R. CFundación Heinrich Böll, Santiago de Chile: ediciones böll y estudios nueva economía.

Alkire, Sabina y James Foster (2011). "Counting and Multidimensional Poverty Measurement". Journal of Public Economics Vol 95 No. 7-8: 476-487.

Alonso, Guillermo (2007). "Acerca del clientelismo y la política social: reflexiones en torno al caso argentino". Revista del CLAD Reforma y Democracia (37):1-10.

Altamirano, Adison y Antonio Lara. (2010). "Deforestación en ecosistemas templados de la precordillera andina del centro-sur de Chile". Bosque (Valdivia),31 (1) 53-64.

Aranco (2018). "Directorio aprueba proyecto MAGA", 24 de julio.

Arauco (2019). Informe de Sostenibilidad 2019 [en línea]. Disponible en <https://www.arauco.cl/chile/wp-content/uploads/sites/14/2017/07/REPORTE_2019.pdf> (consulta: 16 de octubre de 2020).

Arboleda, Martín (2015). "Spaces of extraction, metropolitan explosions: planetary urbanization and the commodity boom in Latin America". International Journal of Urban and Regional Research, 40(1), 96-112.

Armstrong, Herbert y Jim Taylor (2000). Regional Economics and Policy. USA: Editorial Blackwell.

Arriagada, Evelyn (2013). "Clientelismo político y participación local". Polis, 36, 1-20.

Astorga, Luis y Heinrich Burschel (2019). Chile necesita un nuevo modelo forestal. Santiago: Lom. 

Económica.

Bauman, Zygmunt (1999). Modernidad líquida. Buenos Aires, Argentina: Fondo de Cultura

Brundtland, Grom Harlem (1987). Informe Brundtland. Informe de la Comisión Mundial sobre el Medio Ambiente y el Desarrollo [en línea]. Disponible en

$<$ https://www.un.org/spanish/conferences/wssd/desarrollo.htm\#: :text $=\% 22 \mathrm{El} \% 20$ desarrollo $\%$ 20sostenible \%20es\%20el,(Informe\%20Brundtland)\%2C\%201987> (consulta: 16 de octubre de 2020).

Castañeda, Juan (2020). "Escándalos y crisis de confianza institucional en Chile". Tesis del programa de Doctorado en Socialogía. Santiago: U. Alberto Hurtado.

Comisión Asesora Presidencial en Descentralización y Desarrollo Regional, (2014). Propuesta de Politica de Estado y Agenda para la Descentralización y el Desarrollo Territorial de Chile, hacia un país desarrollado y Justo, Santiago, Chile.

Comisión Económica para América Latina y el Caribe (Cepal) (2013). Recursos naturales: situación y tendencias para una agenda de desarrollo regional en América Latina y el Caribe. Santiago, Chile: Cepal.

Comisión Económica para América Latina y el Caribe (Cepal) y Sociedad Alemana de Cooperación Internacional (GIZ) (2012). Seminario internacional sobre: 'Gobernanza de los recursos naturales en América Latina y el Caribe”, Resumen de los debates. Santiago, Chile: CEPAL-GIZ, 24-25.

Daher, Antonio (2003). "Regiones-commodities. Crisis y contagio en Chile". EURE (Santiago) v 29(86):89-108.

Durston, John (2012). "Clientelismo político y actores populares en tres regiones de Chile", En Delamaza y otros, Nueva Agenda de Descentralización en Cbile 369-391. Santiago, Chile.

El Mercurio (2017). Casi 40\% de activos forestales del grupo Angelini ya está fuera de Chile [en línea]. Disponible en

$<$ https://www.elmercurio.com/inversiones/noticias/acciones/2017/12/21/casi-40-de-activos-

forestales-del-grupo-angelini-ya-esta-fuera-de-chile.aspx> (consulta: 16 de octubre de 2020).

Facultad Latinoamericana de Ciencias Sociales (Flacso) (2018). Diagnóstico con Información Secundaria para el Desarrollo Territorial de la Nueva Región de Nuble. Santiago, Chile.

Fawaz, Julia (2000). "Expansión forestal en Nuble y reestructuración social y productiva a nivel local. Percepción de los actores. Revista Universidad del Bío Bío 53-73.

Fernández, Juan, María Fernández y Ricardo Fuentealba (2014). Arreglos político-institucionales para la superación de trampas localizadas de pobreza monetaria: los territorios de Canquenes y Constitución en la región del Maule en Chile [en línea]. Disponible en

$<$ https://rimisp.org/wpcontent/files_mf/1431440287133Arreglospolitico_institucionales_editado. pdf $>$ (consulta: 16 de octubre de 2020).

Figueroa, Eugenio, Rafael Asenjo, Sebastián Valdés y Sergio Praus (2005). "La responsabilidad civil ambiental, el daño al medio ambiente y su valor: Una aproximación legal y económica". Revista de Derecho Ambiental, 2, 69- 95.

Flores, Edwin (2014). Territorios y Estrategia Competitiva, [en línea]. Disponible en<http://www.conectadel.org/wp-content/uploads/downloads/2015/08/5-Territorios-y-EstrategiaCompetitiva-_05_02_15.pdf> (consulta: 16 de octubre de 2020).

Geisse, Guillermo (1990). "Problemas y Dificultades de la Transformación Productiva Conservación Ambiental en cuatro Sectores de la Economía Chilena". En Documento preparado para la División de Medio Ambiente y Asentamientos Humanos de la CEPAL; e Instituto Latinoamericano de Doctrinas y Estudios Sociales (ILADES), Santiago, Chile.

Gudynas, Eduardo (2009). "Diez tesis urgentes sobre el nuevo extractivismo, contextos y demandas bajo el progresismo sudamericano actual", En: Extractivismo, politica y sociedad, coordinador por Jürgen Schuldt, Alberto Acosta, Alberto Barandiarán, Anthony Bebbington, Mauricio Folchi, Alejandra Alayza y Eduardo Gudynas,187-225. Quito: Centro Andino de Acción Popular (CAAP) - Centro Latinoamericano de Ecología Social (CLAES). 
Gudynas, Eduardo (2014). "Los extractivismos en sus contextos globales, regionales y locales". Seminario internacional en Extractivismo en América Latina... agua que no has de beber OLCA y OCMAL. Santiago, Chile, 21 y 22 de agosto.

Harvey, David (2007). Espacios del Capital. Madrid: Akal.

Índice de Desarrollo Regional (IDERE) (2019). Índice de Desarrollo Regional. Santiago: ICHEMUniversidad Autónoma.

Industria Forestal (Infor) (2019). Anuario Forestal 2019 [en línea]. Disponible en $<$ https://wef.infor.cl/publicaciones/anuario/2019/Anuario2019.pdf > (consulta: 16 de octubre de 2020).

Instituto de Estudios Urbanos y Territoriales de la Universidad Católica (2019). Índice de Calidad Vida Urbana (ICVU). Santiago: PUC-Cámara Chilena de la Construcción.

Instituto Nacional de Estadística (INE) (2017). Censo 2017 [en línea]. Disponible en $<$ http://resultados.censo2017.cl/Region?R=R16> (consulta: 16 de octubre de 2020).

Lander, Edgardo (2014). El Neoextractivismo como modelo de desarrollo en América Latina y sus contradicciones. Disponible en <https://mx.boell.org/sites/default/files/edgardolander.pdf> (consulta: 16 de octubre de 2020).

Machinea, José Luis y Cecilia Vera (2006). Comercio, inversión directa y politicas productivas [en línea]. Disponible en <http://cdi.mecon.gov.ar/bases/doc/cepal/espec/16.pdfCepal> (consulta: 16 de octubre de 2020).

Mayol, Alberto (2013). El Derrumbe del Modelo. Santiago, Chile: Lom.

Mayol, Alberto (2016). Autopsia, Santiago, Chile: Catalonia.

Méndez, Karen (2016). "El rol de la identidad territorial de las cepas tradicionales en la reconfiguración socio -espacial del Valle del Itata". Tesis para optar al grado de magíster en geografía. Santiago, Chile: Facultad de arquitectura y urbanismo, Universidad de Chile. Ariel S.A.

Méndez, Ricardo (1997). Geografía Económica. La lógica espacial del capitalismo global. Barcelona: Editorial

Ministerio del Trabajo (2019). Sistema de Información Laboral (SIL) [En línea]. Disponible en $<$ http://www.sil.mintrab.gob.cl/> (consulta: 16 de octubre de 2020).

Ministerio de Desarrollo Social (2015). Encuesta de Caracterización Socioeconómica Nacional (CASEN) [en línea]. Disponible en <http://observatorio.ministeriodesarrollosocial.gob.cl/casenmultidimensional/casen/casen_2015.php> (consulta: 16 de octubre de 2020).

Ministerio de Desarrollo Social (2015). Reportes comunales bon [en línea]. Disponible en $<$ http://reportescomunales.bcn.cl/2017/index.php/Ninhue/Salud> (consulta: 16 de octubre de 2020).

Ministerio de Desarrollo Social (2016). Informe de Desarrollo Social [en línea]. Disponible en $<$ http://reportescomunales.bcn.cl/2017/index.php/Ninhue/Salud> (consulta: 16 de octubre de 2020).

Ministerio de Desarrollo Social (2017). Encuesta de Caracterización Socioeconómica Nacional (CASEN) [en línea]. Disponible en

$<\underline{\text { http://observatorio.ministeriodesarrollosocial.gob.cl/casenmultidimensional/casen/casen 2017.p }}$ hp> (consulta: 16 de octubre de 2020). Ediciones B.

Mönckeberg, María Olivia (2001). El saqueo de los grupos económicos al Estado de Chile. Santiago:

Muñoz, Andrés, Gustavo Radics y Bone, Claudia (2016). "Subnational Fiscal Disparities and Intergovermental Transfers in LAC”. Hacienda Pública Española, IEF, vol. 219(4), 35-66.

Organización para la Cooperación y el Desarrollo Económicos (Ocde) (2015). Estudios económicos de la Ocde Chile [en línea]. Disponible en <http://www.oecd.org/economy/surveys/Chile-2015-visiongeneral.pdf $>$ (consultada: 21 de octubre de 2020). Ocde.

Ojeda, Carolina, Rodrigo Cancino, Camila Carabante, Jasna Cisterna y Daniela Díaz (s.f.). "Percepción del bienestar y el paisaje visual en zonas de industrias celulosas: caso de estudio en nueva aldea, Chile". Planeo Artículos Territoriales, 1-11.

Organización de las Naciones Unidas (ONU) (1992). Declaración de Río sobre el Medio Ambiente y el Desarrollo [en línea]. Disponible en 
$<: / /$ www.un.org/spanish/esa/sustdev/documents/declaracionrio.htm $>$ (consulta: 16 de octubre de 2020) ONU. CECSA.

Porter, Michael (1997). Ventaja competitiva: Creación y sostenimiento de un desarrollo superior. México:

Porter, Michael y Mark Kramer (2006). "Estrategia y Sociedad, El vínculo entre ventaja competitiva y responsabilidad social corporativa". Harvard Business Review, Vol. 84, (12), 42-56.

Portillo, Luis (2014). "Extractivismo clásico y Neoextractivismo, ¿dos tipos de extractivismos diferentes?" Tendencias Vol. XV (2) ,11-29.

Ramos, Virginia. (2014). "La crisis del salmón y las contradicciones de las industrias extractivas en el sur de Chile". Tesis de doctorado en Estudios Latinoamericanos, Universidad ARCIS, Santiago, Chile.

Sabatini, Francisco, Francisco Mena y Patricia Vergara (1997). "Otra vuelta a la espiral: El conflicto medio ambiental de Puchuncaví bajo democracia”. Ambiente y Desarrollo, XII (4), 30-40.

Salazar, Gabriel (2003). Historia de la Acumulación Capitalista en Chile. Santiago: Lom.

Salinas, Sergio y Rolando Garrido (2003). "Paradoja de la democracia: manejo de conflictos y violencia en una cultura autoritaria”. En América Latina: Conflicto, violencia y paz en el siglo XXI, coordinado por Eduardo Sandoval y Robinson Salazar, (190-199). Buenos Aires, Argentina.

Disponible

Senado de la República de Chile (2015). Datos de Unidad Presupuestaria del Senado [en línea].

en<https://www.senado.cl/site/presupuesto/2017/cumplimiento/tematicos/Ingresos $\% 20$ Municipales $\% 20$ per $\% 20 \mathrm{C} \% \mathrm{C} 3 \%$ A1pita.pdf> (consulta: 16 de octubre de 2020).

Sistema de Medición de la Calidad de la Educación (SIMCE) (2018). agenciaeducacion.cl [en línea]. Disponible en <http://informacionestadistica.agenciaeducacion.cl/\#/bases $>$ (consulta: 16 de octubre de 2020).

Sistema Nacional de Información Municipal (SINIM) (2018). Revista Presupuestaria año 2018 [en línea]. Dsiponible en

<http://www.sinim.gov.cl/archivos/home/597/Revista_Presupuestaria_UIM_2018_(final)2.pdf> (consulta: 16 de octubre de 2020).

TheClinic (2015). El historial de conflictos ambientales del grupo Angelini [en línea]. Disponible en <https://www.theclinic.cl/2015/08/23/el-historial-de-conflictos-ambientales-del-grupo-angelini/> (consulta: 16 de octubre de 2020).

Terram (2014. Sacrificando Chile Por la Inversión Presidenta: ¿Zonas de sacrificio o justicia ambiental?. [en linea]. Disponible en <bttps://www.terram.cl/descargar/balance_ambiental/Balance-Ambiental-2014-Sacrificando-Chilepor-la-inversion-Presidenta-z̧onas-de-sacrificio-o-justicia-ambiental.pdf> (consulta: 16 de octubre de 2020).

Valenzuela, Esteban y Paola Yévenes (2015). “Aproximación al concepto de cooptación política: la maquinaria presicrática y sus formas". Polis, 14, 469-488.

Valenzuela, Esteban y Yanina Kowszyk (2017). "Extractivas en transformación por la resistencia territorial en Chile: Giro 3 V", Polis, 48, 291-316.

Vergara-Perucich, José (2018). "Aplicaciones de la teoría implosión/explosión: relación entre la Región Metropolitana de Santiago de Chile y los territorios productivos regionales". Revista EURE - Revista De Estudios Urbano Regionales, 44(133): 71-90.

Vidal, Álvaro (2007). "Las acciones emanadas del daño ambiental y el régimen de responsabilidad aplicable". Cuadernos de Análisis Jurídico, (4) ,191-210.

Zapata, Francisco (2001). "El trabajo en la vieja y en la nueva economía". En el futuro del trabajo - el trabajo del futuro coordinado por Enrique de la Garza y Julio Neffa, (99-110). Buenos Aires: CLACSO. 